any other solvent or substance whatever Bandages containing a particle of any material besides these two are not "Martin's bandages," and I disclaim, utterly and decidedly, all responsibility for effect, or want of effect, observed in their use. In every paper that I have written on the use of pure rubber bandage, I have most explicitly stated the composition of the bandages which I recommend, and have so long and with such extraordinary success employed. I have also stated my perfect willingness to afford information to inquiring correspondents, and expressed the hope that "manufacturers may produce the bandages at the lowest paying price, but that they will not do this at any sacrifice of labour in making or of excellence of material." My experience here in America convinced me that the desire among dealers to obtain bandages which they could sell at a very low price, and still with large pecuniary profit, led to the manufacture of an article which, however attractive in appearance, was not fit to be used, and which proved utterly deficient in the very important quality of durability. It was this knowledge that induced me to write the communication from which the quotation is made. Soon after it was written, I began to receive by every steamer letters from England complaining of the inferior quality of the English-made bandages, the failure to fully obtain the effects $I$ had claimed in my first paper, and which the writers obtained after they had procured bandages which had been inspected and approved by myself. Some of these writers spoke of absolutely injurious effects induced by the use of the English-made bandages-as, for instance, the severe and complete vesication of the whole leg by a few hours' application of one of them. A few of these letters contained little pieces of the bandages complained of, which were certainly very bad indeed; and two or three of the writers strongly urged me, in justice to myself and for the protection of British practitioners, to write on the subject to one of the leading London medical journals. I was very reluctant to do this. I hoped that the worthless and injurious bandages complained of might be exceptional, and that practitioners would soon learn to avoid them. At last, however, I became convinced that all the rubber bandages manufactured at that time in England were objectionable; that they were so because manufacturers did not appreciate the absolute necessity that they should be made in a certain way, carefully excluding ingredients in general use in the English rubber manufacture; and because also, notwithstanding the offer I had made, they had not thought it worth while to apply to me for instruction or direction; and that it was a duty, no longer to be shirked, to make these facts known. I accordingly, in the latter part of last December, wrote a "lengthy communication" to the journal in which Mr. Home's paper appeared, on the fact of the inferiority of the Englishmade bandages and the reasons for that inferiority, and informing English practitioners that, in pure self-defence, and quite contrary to my intention at the time my first paper was published (October 26th, 1878), I had been driven into the manufacture of pure rubber bandages; and also affording information where, in London, such bandages, made for and fully inspected by myself, and, as a guarantee of this, stamped with a fac simile of my signature, could be obtained. This paper was not published, its receipt was not even acknowledged in the usual way, nor was any notice whatever taken of it for over three months after its date, over two months after its receipt by the editor. Shortly after writing this lengthy communication, I received specimens of whole bandages, an examination of which so fully and authentically confirmed all, and more than all, that I had written, that I wrote a second letter on the subject to the editor, which, however, noticing that the receipt of my first epistle was not acknowledged, I refrained from sending. On the 15th March, a short editorial note appeared in the aforesaid journal, in which a most imperfect and brief allusion was made to my paper which had been in the editor's hands for over two months, concluding with these words : "To speak quite candidly, we would say that in all the respects of which Dr. Martin speals-smoothness, elasticity, substance, excellence of material and manufacture-they" (the English-made bandages) " are superior to those which are imported with his signature." I immediately wrote to the editor a full statement of what I knew about English-made bandages, accompanied by eleven samples, an examination of which could not fail to convince him that he had hastily reached and expressed convictions which were unjust and, however unwittingly, untrue, and calculated to do not only a great wrong to me and the method I had originated and commended, but also to the English profession, which would undoubtedly be led by such assurances to a confidence ouly to be rewarded by disappointment or very partial success, as in Mr. Home's case. I asked the editor to calmly and carefuily, as the importance of the subject demanded, examine and compare the data I furnished him, and in mere justice and common fairness, as some slight reparation to me, publish the whole of my communication, however "lengthy," without abridgment. As I knew that he might not accede to this request, however just and moderate, I added a full statement of the case, together with the letter itself, to a very large edition of that paper which was presented to the American Medical Association in June, 1877, in which I first publicly amnounced my method of treatment by the pure rubber bandage. This pamphlet is now ready, and will leave here to-morrow, and probably reach London as soon as this communication, and, without doubt, be on sale before this paper can possibly be published or acknowledged in print. To that pamphlet I refer for full iuformation as to the method of treatment I recommend and the fuller details and information touching the why and the wherefore of the wide difference of effect following the use of rubber bandages which are what they ought to be, and those which are the reverse.

Boston, U.S.

\section{COMPLETE TRANSPOSITION OF THORACIC AND ABDOMINAL VISCERA.}

By W M. CU P P A N, SURGEON-MAJOR A.M.D.

THE publication in a late number of TEE LANCET of a case of transposition of viscera has indnced me to submit an account of a similar case that occurred in the practice of Surgeon (now Surgeon-Major) A. Skeen, M.B., Bengal Army, who was at the time-August, 1873-acting civil sugeon of Peshawur, and to whose courtesy I am indebted for the use of it. Nothing of the kind was suspected during life, but the appearances were so striking and obvious on section as to startle the native Mehter, or scarifier, who prepared the remains for his inspection, and yet were they less pronounced than some other instances of like import that have been published. The last-named functionary was the first to inform Dr. Skeen that, to translate his own words, " everything is topsy-turvy, upside-down, sir, in this man's body." The circumstances under which this discovery was made were as follows (and I purposely condense the report as much as possible to save space) :-

A native, named Madho, who died suddenly while in the act of romiting, had been admitted to the local dispensary the previous day-August 17th, 1873-for what the native doctor regarded and treated as a colic. The patient stated that he had been taken ill the day before, after partaking of a meal of Makhi- (Indian corn) bread, ${ }^{1}$ and butter-milk, and that there had been much abdominal pain and vomiting ever since. The vomited matter was slightly feculent, notwithstanding that the use of an enema was followed by more than one discharge of scybala, and that he felt otherwise relieved by the treatment employed. But the relief was only temporary : he was cold and almost pulseless, but quite free from other uneasiness, when seen that evening by Dr. Skeen; and he died, collapsed, about 11 the same night.

A propos of the occasionally poisonous properties of this and other Indian cereals, it is related of the late Colonel Tod, in the Memoir of the Author that is prefixed to his "Travels in Western India" (p. xxxviii.) that he suffered from a feeling of expansion of the head, tightness and swelling of the tongue, and constriction of the throat, on partaking of two mouthfuls of a cake of this material. And Dr. Irvine mentions, in the "General and Medical Topography of Ajmere" (pp. 88-9), that "the whole inhabitants" of certain villages in that country "become periodically maniacal" after consuming two small and inferior sorts of rice that are called Kootkie and Koodhoo. "Death:" he adds, "occa sionally follows the use" of them; and we know that similar results are produced by cockspurred wheat and rye nearer home. Dr. Chevers has also, I think, alluded to this contingency in his well-known "Manual of Jurisprudence for India"; and Dr. Irvine has traced numerous cases of paralysis and paraplegia in the north-west to the injurious effects of Kessaree Dal, alias Lathyrus sativus, in the "Indian Annals of Medical Science" (Nos. xii., xili., xiv., and xxiii.) 
The post-mortem appearances were as follows:- The brain-substance was more than usually congested, but othermise healthy. On raising the anterior wall of the thorax the heart was found to be much higher in the chest than was natural; its base was found lying on a level with the second rib of the right side and the right half, taken perpendicularly, of the sternum, and consequently encroaching on the right lung. This latter had much the appearance and formation of the left lung, and the descending aorta pursued its course down the right side of the dorsal vertebræe, to the extent usual in ordinary cases, on the opposite one. The heart itself, which only weighed eight ounces, was structurally healthy; but the right ventricle was all but filled with a fibrinous, entirely decolorised clot, which also extended into the auricle, and Dr. Skeen attributed the suddenness of this man's death to the obstructive agency of this clot. On opening the abdomen, the liver and spleen were found to have changed places, the former lying on the left side, the latter on the right. The omentum was greatly congested; so also were the small intestines : but there was no appearance of enteritis in them, or of effusion into the cavity of the peritoneum, and they were distended with air or partially filled with fluid matter. The stomach, also full of liquid, was found lying with its pyloric end directed to the left side, and the small intestines were followed from this to their termination, in the usual way, in the rectum. The latter, however, lay on the right side of the sacrum, instead of, as is usual, on the left; and "the gut was occluded above the ileo-cæcal valve by a not very extensive intussusception." The mucous membrane of both bowels exhibited several congested spots ; and, "except that the left lobe of the liver was of the usual size and but faintly marked out, whereas one might, from the general transposition of the parts, look for a small right lobe and a large left one," there was nothing else abnormal in either.

I published an illustrated case of a peculiar congenital displacement of the stomach into the chest in THE LANCET for Dec. 29th, 1869, which led to convulsions and death from extravasation of blood on the brain. No vomiting could be ever induced in this case, but its subject was always known to be puny and delicate, and the viscus itself "was comcletely displaced upwards through an opening in the diaphragm-that bore no evidence of any recent rent, rupture, or laceration, - and occupied a position in front of the left lung, which latter it had so compressed against the spine as to reduce its weight to six ounces, while the right weighed twenty-two ounces and a half." The heart was also displaced downwards and to the right. The left kidney occupied the place usually assigned to the spleen, which was itself found lying within the cavity of the thorax. Several coils of intestine were found in the same locality. Some of these were doubtless displaced through the straining that preceded death; while others were, it may be, dragged up by the pylorus, which was closely jammed under the left clavicle; and, in either case, the position of the stomach, "encased as it was in a comparatively immovable cavity, and beyond the reach of abdominal or diaphragmatic agency," will readily account for its insusceptibility to emetics during life, if it does not help to shed some light on the physiology of vomiting generally.

The collapse and sudden, but withal painless, sinking that ushered in death in this case has since enabled me to diagnose, with some confidence, cases in which there was a traumatic rupture of the bowel, or in which an ulcer of the stomach had terminated in perforation; and the nervous paralysis or default that underlies these several conditions is, I believe, substantially the same in all. However that may be, I and others who saw this poor lad in the dead-house at Pembroke Dock, South Wales, were very hard on the practitioner (a civilian, I believe) who passed him into the service, for overlooking so obvious a complication. Had I known as much of recruiting then as I do now-I have examined no less than 500 recruits since I came here towards the end of March last-I would have been more sparing of my censure, and it is a question with me if this kind of displacement or transposition affects injuriously the health or viability of its owner. Any how, the subject deserves further investigation, both from a recruiting and an insurance as well as from a physical or teratological point of view ; and I may be here permitted to quote, in connexion with it, the case of "a most active," and at the same time apparently "very eminent," Dublin specialist, whose heart is (according to a writer in THE LANCET of Jan. 21st, 1863), " undoubtedly and congenitally placed in the right thoracic region," The gentleman referred to was "fully persuaded himself," the letter adds, "that his liver occupies the left hypochondrium," and I am not, I trust, singular in expressing a hope that he still continues to " enjoy the excellent health" with which he was credited at the time indicated above by his admirin biographer "F.P.C.S.I."

Station Hospital, Warrington.

\section{CASE OF MALIGNANT REMITTENT FEVER。}

Bx D. L. MACKENZIE, I.R.C.P. \&c.,

FORMERLY HOUSE-PHYSICIAN AND HOUSE-SURGEON TO THE ROYAL INFIRMARY, EDINBURGH.

THE following case may be interesting in view of the late epidemic of yellow fever on the banks of the Mississippi, and its present prevalence at the French settlements of Dacca and Goree on this coast. It is a typical case of the severest form of malarious fever, of rare occurrence, and although very similar to yellow fever, can, I think, be readily distinguished from it. It is interesting, also, on account of the proximity of yellow fever to these parts, and because an epidemic of this disease nsually appears on the West Coast of Africa every sixth or seventh year, as the epidemics of 1860,1866 , and 1873 testify, when fully onehalf of the European residents succumbed to its ravages. In 1872 the epidemic, which in the following year visited Calabar, Bonny, and the other large rivers in this part of the coast, commenced in Senegambia and Sierre Leone, and it is feared that ere long the same track may be taken by the deadly scourge. So far, the settlements in this neighbourhood have, with the exception of Lagos, been comparatively healthy; but in the latter place, during the months of April, May, June, and July, nearly one-third of its entire European population died from fever and dysentery alone.

Thomas C—, aged twenty-seven, a Scotchman by birth, of delicate constitution, had, after considerable exposure to fatigue and malarious influences, complained of fever of an intermittent type for fire days, accompanied by constipation of bowels and sleeplessness, which, on Oct. 9th, culminated in a rigor of more than usual severity. He had frequently suffered from malarious fevers previously. Bowels had been freely opened by means of a simple enema. Oñ visiting him I found the cold stage had given place to the hot. He was suffering from high fever. The pulse was rapid (130), weak, and compressible ; temperature $105^{\circ}$; skin hot and dry, of a bright-yellow hue all over the body. There was great precordial oppression, with nausea and vomiting of blood. The urine also contained blood, and the same material was passed in large quantity by the bowels. The liver and spleen were teuder on heavy pressure, but not painful ; they were slightly enlarged, probably not more so than in an ordinary case of uncomplicated remittent. There was no headache, but great restlessness prevailed; tongue dry, and covered with a brown fur ; thirst intense. Seeing that hæmorrhage was the most serious symptom, I administered gallic acid in fifteen-grain doses, repeated every four hours ; cold was applied to the head, and enemata of beeftea and port-wine were also administered; champagne, and occasionally diluted lime-water, were allowed. Evening: All bleeding stopped. Patient very hot and restless. Vomiting of bile very distressing. Bowels repeatedly open ; stools bilious; nausea and oppression at the epigastrium very severe. No pain complained of anywhere except in the small of the back. Thirst intense ; effervescing draughts, with chloroform, were ordered to be given at short intervals. A sinapism was applied to the epigastrium, and the injections to be given every hour.

Oct. 10th.-Patient much exhausted. Pulse very weak and rapid ; temperature nearly $106^{\circ}$; tongue dry and brown; vomiting and thirst urgent. Urine dark-coloured, containing blood and bile; stools and matters vomited also con. tained large quantities of bile. The yellow tinge of skin if anything brighter than yesterday. Brandy was substituted for port wine in the enemata, and fifteen grains of sulphate of quinine were ordered to be added to three of these during the course of the day.

11th.-Patient much the same. Restlessness, with vomit 